\title{
Facile Synthesis of Hierarchically Structured MIL- 53(Al) With Superior Properties Using An Environmentally-Friendly Ultrasonic Method For Separating Lead Ions From Aqueous Solutions
}

Niusha Ahadi

Islamic Azad University, Science and Research Branch

Sima Askari ( $\sim$ sima.askari@srbiau.ac.ir)

Islamic Azad University, Science and Research Branch

Amir Fouladitajar

Islamic Azad University, Science and Research Branch

Iman Akbari

Islamic Azad University, Science and Research Branch

\section{Research Article}

Keywords: investigate, ultrasonic, adsorption, synthesized, aqueous

Posted Date: October 25th, 2021

DOl: https://doi.org/10.21203/rs.3.rs-983981/v1

License: (1) (1) This work is licensed under a Creative Commons Attribution 4.0 International License.

Read Full License 


\title{
Facile synthesis of hierarchically structured MIL-53(Al) with superior properties using an environmentally-friendly ultrasonic method for separating lead ions from aqueous solutions
}

\author{
Niusha Ahadi ${ }^{\mathrm{a}}$, Sima Askari ${ }^{\mathrm{a}, *}$, Amir Fouladitajar $^{\mathrm{a}}$, Iman Akbari $^{\mathrm{a}}$ \\ ${ }^{a}$ Department of Chemical Engineering, Science and Research Branch, Islamic Azad University, Tehran, Iran \\ * Corresponding author; E-mail address: sima.askari@srbiau.ac.ir
}

\begin{abstract}
The present study aims to investigate novel ultrasonic synthesized MIL-53(Al) and its applications in adsorption. Both conventional and ultrasonic methods were used to synthesized Mil-53(Al). The ultrasonic-assisted synthesis procedure results in reducing synthesis time to 24 hours; however, Compared to that conventional method takes 3 days to create the framework. Applying ultrasonic waves also increases surface area to $50 \%$ more than the ones synthesized by the conventional method, as well as creating the hierarchical MIL-53(Al) structure (meso- and micro-) pores. To this end, XRD, FESEM, BET, and FTIR analyses were employed to identify and characterize MIL53(Al). The unique structure and high MIL-53(Al) yield lead to effective adsorption among MOF and lead ions. The optimum conditions for removing lead were $6.0 \mathrm{pH}, 20 \mathrm{mg} / \mathrm{l}$ concentration, 60.0 min contact time, $0.04 \mathrm{~g}$ adsorbent dose, and 318k temperature with $97.63 \%$ removal of the lead ions. The experimental adsorption equilibrium and kinetic data fitted the Langmuir isotherm and pseudo-second-order kinetic models, respectively. Moreover, the use of ultrasonic synthesized MIL-53(Al), for the first time as a novel adsorbent in heavy metal removal, pointed to the great potential of this new environmentally-friendly adsorbent in removing lead ions from aqueous solutions.
\end{abstract}




\section{Introduction}

Due to the fast development of trade and expansion of urbanization over the last few decades, pollution of surface and groundwater with heavy metals and their adverse effects on the health of living organisms as well as the consequent problems, have received considerable attention $^{1}$. Among all heavy metals, lead is one of the most toxic elements. Lead is used as a significant raw material used in many industrial production operations such as batteries, radiation devices, solar cells, ceramics, and paint industries. Lead can cause nervous disorders such as IQ decline. In addition, it causes anemia and further side effects such as autoimmunity ${ }^{2}$,headache, insomnia, liver and kidney problems, gastrointestinal, and nervous system disorders, to name a few ${ }^{3,4}$. Therefore, $\mathrm{Pb}$ (II) decontamination of the contaminated water before being discharged into the water reservoir from industrial plants is of high significance.

A number of techniques such as adsorption, chemical precipitation, coagulation, membrane filtration, ion exchange, electro-reduction are employed to remove heavy metals from wastewater. Compared to other techniques in water treatment, adsorption is a more appropriate option because of its simplicity, efficiency, and economy ${ }^{5,6}$.

Different adsorbents have been developed to remove dissolved materials from the solution using ion adsorption mechanisms. In this regard, preparing a promising adsorbent is considered a significant challenge. Nano-porous compounds such as Metal-Organic Frameworks (MOFs) have received significant attention in recent years due to their vast contact surface areas, solvent stabilities, high porosity, well-organized pores, and regular particle size ${ }^{7-9}$. Further, MIL-53 is a group of MOFs produced by the Lavoisier Institute, which is a white powder with the chemical formula of $[\mathrm{Al}(\mathrm{OH})[(\mathrm{O} 2 \mathrm{C})-\mathrm{C} 6 \mathrm{H} 4-(\mathrm{CO} 2)]$. Owing to the unique surface area, porosity, pores shape, size tunability, and adsorptive nature, MIL-53(Al), among the MILs family, can efficiently stimulate the scientific society ${ }^{10,11}$. MOFs are used in different fields such as catalysis, separation, gas storage, and drug delivery. Few studies have been conducted on their applications as the adsorbents used for removing hazardous substances such as volatile organic compounds and dyes from aqueous solutions ${ }^{12-14}$. The adsorption performance depends mainly on several characteristics such as crystallization, particle size, and availability of the functional groups. Since smaller particle sizes have additional surface availability, they cause higher adsorption capacity. 
In the present study, MIL-53(Al) was synthesized through a novel environmentally-friendly method using ultrasonic waves to enhance the energy efficiency of material synthesis, decrease the reaction time and even temperature. The method mentioned above will also increase the surface area of the adsorbent, which will contribute to a promising adsorbent that is a time and energy consumer to form a framework and boosts the adsorbent features in order to remove lead ions from aqueous solutions. Moreover, this study employed the adsorption technique to eliminate lead ions from the solution. This technique was also investigated using the kinetic and isotherm approaches. Of note, the effects of solution temperature, $\mathrm{pH}$, and adsorption dosage on removal efficiency were tested.

\section{Materials and methods}

\section{Materials and reagents}

The primary materials used in the synthesis and adsorption tests were of analytical reagent grade. Aluminum (III) nitrate nonahydrate (Al-(NO3)3·9H2O) and 1,4-BenzeneDiCarboxylic (BDC) acid were used as $\mathrm{Al}($ metal) sources and organic ligands, respectively, which were purchased from Merck, Germany. In addition, N, N-Dimethylformamide (DMF), methanol (CH3OH), Hydrochloric acid $(\mathrm{HCl})$, and sodium hydroxide $(\mathrm{NaOH})$ were acquired. Moreover, the source of lead ions was [Pb(NO3)2] procured from Merck, Germany. Deionized (D.I.) water was used to prepare all solutions.

\section{Preparation of hierarchically structured MIL-53(Al)}

The present study employed a new environmentally-friendly method for ultrasonic-assisted synthesis (UAS) of MIL-53(Al). According to this method, $(6.5 \mathrm{~g})$ Aluminum (III) nitrate nonahydrate (AI(NO3)3.9H2O) (98\% purity) and (1.44 g) 1,4-BenzeneDiCarboxylic (BDC) acid (98\% purity) with $25 \mathrm{ml}$ of

D.I water were stirred for 10 minutes at room temperature until complete dissolution is achieved. The mixture was then exposed to ultrasonic waves of $24 \mathrm{kHz}$ and $100 \%$ intensity for 30 minutes after dissolving and then, it was transferred to $100 \mathrm{ml}$ autoclave with black Teflon liner steel. Finally, an oven was used to heat the sample to $220^{\circ} \mathrm{C}$ for 24 hours. The autoclave was cooled down. Then, the solid phase was separated using a centrifuge, and $35 \mathrm{ml}$ of DMF solution (solid solvent) was added to remove unreacted terephthalic acids trapped in the pores of the samples. The autoclave was put back in the oven to be 
heated to $150^{\circ} \mathrm{C}$ for 12 hours. Finally, the solid phase was separated by centrifuge and washed with methanol; then, $40 \mathrm{ml}$ of methanol was added to the sample, and the sample was dried in an oven at 150 ${ }^{\circ} \mathrm{C}$ overnight. The result is a solid white powder subjected to different analyses used for identifying and ensuring the correct formation of MIL-53 (Al). In the end, the synthesized crystals were calcined at $650 \mathrm{~K}$ in the air for $5 \mathrm{~h}$. In order to synthesis MIL-53(Al) with the conventional (CS) method, the primary mixture, including water, BDC, and Aluminum(III) nitrate nonahydrate with the same amount as ultrasonic synthesis, was stirred for 1 hour at room temperature until complete dissolving and then transferred to $100 \mathrm{ml}$ autoclave with black Teflon liner steel and used the oven to heat the sample to $220^{\circ} \mathrm{C}$ for 72 hours. The autoclave was let to be cooled down; all the other experimental conditions took place the same as the ultrasonic synthesis method.

\section{Characterization}

The morphology and composition characteristics of MIL-53(Al) were evaluated using Field Emission Scanning Electron Microscopy (FESEM) and a Seron AIS2100. In addition, X-Ray Diffraction (XRD) was employed to examine the crystalline structure recorded by the PW1730 diffractometer with $\lambda \mathrm{CuK} \alpha=1.54056 \mathrm{~A}^{\circ}$ and a step size of 0.05 at $40 \mathrm{kV}$ and $30 \mathrm{~mA}$. The BELSORP MINI 11 instrument measured the Brunauer-Emmett-Teller (BET) analysis within the nitrogen adsorption-desorption isotherm method at $(77 \mathrm{k})$ in order to detect structural properties of MIL-53(Al). Fourier-Transformed Infrared spectroscopy (FT-IR) was obtained using the PERKIN EKMER instrument at a resolution of $400-4000 \mathrm{~cm}-1$. Further, AAS was used to measure the lead concentration using Model 3110 Perkin Elmer Atomic Absorption Spectrometer. The pH meter model, combined with a pH electrode, was of the $827 \mathrm{pH} \mathrm{Lab}$ (Metrohm, Swiss).

\section{Preparation of lead solutions}

Millipore/D.I. water and lead (II) nitrate were used to prepare the lead stock solution with a concentration of $1000.0 \mathrm{mg} / \mathrm{L}$. Other lead solutions with different concentrations were freshly prepared for each experiment using the stock solution.

\section{Evaluation of Adsorbents Performance}

MIL-53(Al) adsorption capacities for $\mathrm{Pb}(11)$ were presented at different dosages with known initial concentrations for fixed values of time, temperature, and $\mathrm{pH}$. When the solution reached equilibrium, two solid and liquid phases were divided through filtration and then, Atomic 
Absorption Spectrometer (AAS) was employed to determine the remaining concentration of the $\mathrm{Pb}$ ions in the solution. The $\mathrm{pH}$ of point of zero charges (pHpzc) of MIL-53(Al) was calculated by the method proposed by Faria et al. ${ }^{15}$. The effect of initial $\mathrm{pH}$ on lead ion adsorption was also examined at different $\mathrm{pHs}$ ranging from 2.0 to 7.0. The $\mathrm{pH}$ of the solution was fixed by adjusting $\mathrm{HCl}$ and $\mathrm{NaOH} 0.1$ and $0.01 \mathrm{M}$ to the solutions. Then, $0.04 \mathrm{~g}$ of MIL-53(Al) was added to every $40 \mathrm{ml}$ of solution, and the agitation samples were placed on an incubator shaker at a speed of 315 rpm for three hours and at room temperature. Eventually, the final concentration of lead ion was analyzed using AAS.

Further, $\mathrm{Pb}$ adsorption isotherm and other practical parameters were studied in the following experimental conditions: the concentration of 10-130 (mg/L), time range of 3.0-180.0 min, and different temperatures of $288,298,308$, and $318 \mathrm{~K}$. The adsorbent dosage ranges from 0.001 to $0.04 \mathrm{~g}$. The kinetics investigations for $\mathrm{Pb}(1 \mathrm{l})$ removal were evaluated through the analysis of $\mathrm{Pb}$ adsorption in different time periods. The rates of metal ions ( $\mathrm{R} \%)$ removal and removal capacity of $\mathrm{Pb}(\mathrm{II}) \mathrm{qe}(\mathrm{mg} / \mathrm{g})$ were determined using equation (1) and equation (2), respectively ${ }^{16}$ :

$$
\begin{aligned}
& \text { Removal\% }=\frac{C_{0}-C_{e}}{C_{0}} \times 100 \\
& q_{e}(m g / g)=\left(C_{0}-C_{e}\right) \times \frac{V}{m}
\end{aligned}
$$

In which $\mathrm{V}(\mathrm{ml})$ is the volume of lead ion solution; $\mathrm{m}(\mathrm{g})$ is the amount of MIL-53(Al); and C0 and $\mathrm{Ce}$ are the initial and equilibrium concentrations $(\mathrm{mg} / \mathrm{L})$ of lead ion adsorbed, respectively.

\section{Result and discussion:}

\section{MIL-53(Al) characterization}

The XRD pattern of the synthesized MIL-53(Al) is presented in Figure 1. These patterns are very similar to the previous one reported in reference ${ }^{17}$. The XRD pattern of the UAS and CS MIL$53(\mathrm{Al})$ in this study shows the prominent characteristic peaks at $2 \theta=9.38^{\circ}, 12.58^{\circ}, 17.93^{\circ}, 23^{\circ}$ $48,25.28^{\circ}, 27.33^{\circ}$, which match the peaks reported in the literature ${ }^{17}$, indicating that MIL-53(Al) is well crystallized and synthesized. Also, the difference in peak intensities is due to higher 
ultrasonic energy as a driving force, increasing nucleation rate and leading to a considerable amount of cavitation bubbles ${ }^{18}$.

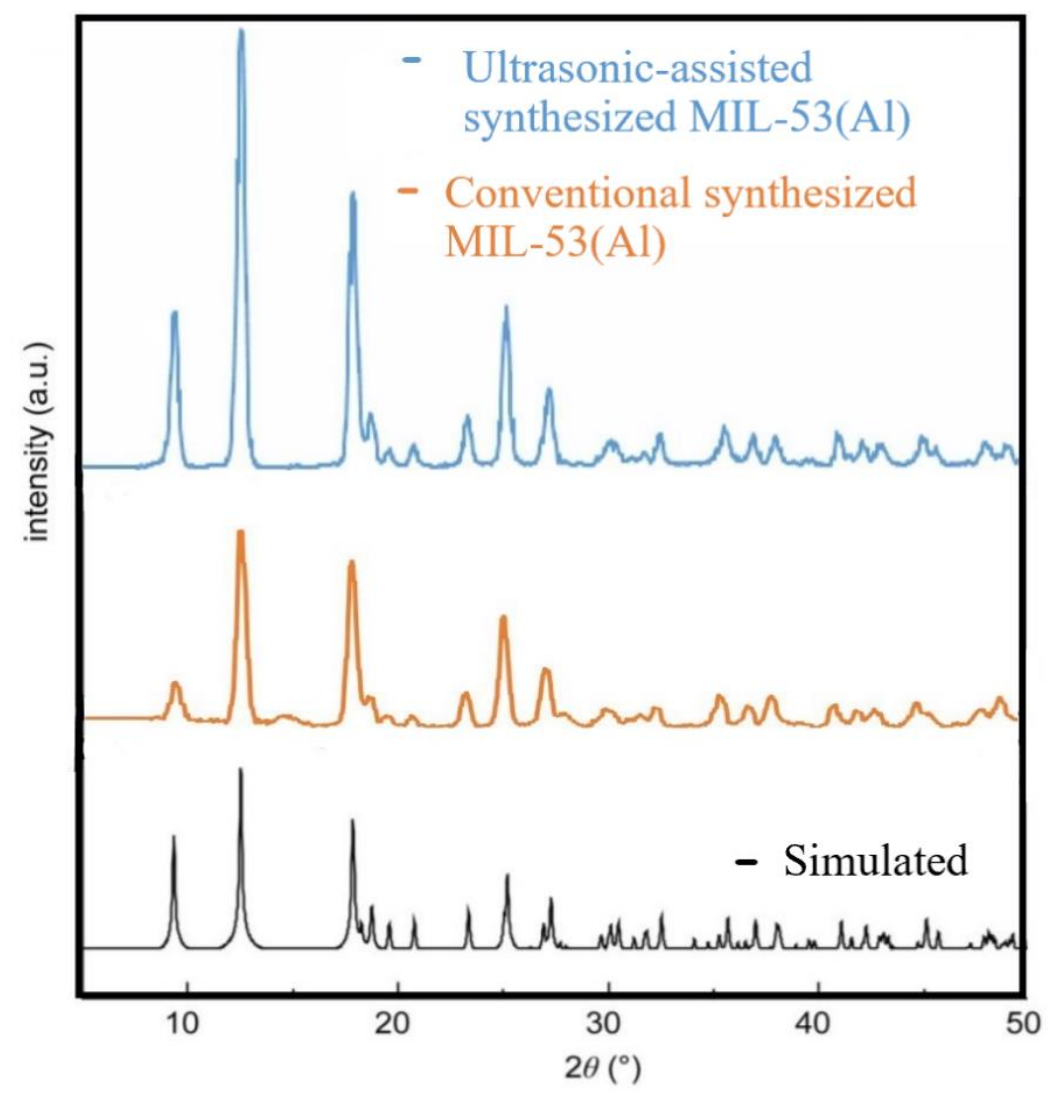

Figure 1. X-ray diffractograph of the ultrasonic and the conventional synthesized MIL-53(AI).

The morphology of UAS and CS MIL-53(Al) samples with different magnifications were examined using FESEM, the results of which are presented in Figure 2. According to this figure, the samples synthesized through the sonochemical method have octahedral shapes with crystallike structures. Such structures are not aggregated; instead, they have a more uniform particle size which is smaller than the sample obtained by the conventional hydrothermal method. According to the standard conditions required for MOF crystal growth, faster nucleation rates result in smaller crystal sizes ${ }^{19}$. Following the FESEM characterization results, the sonochemical synthesized MIL53( $\mathrm{Al})$ has smaller uniformly distributed nanoparticles mainly because of the accelerated nucleation and shorter synthesis time required for sonochemical synthesis. 

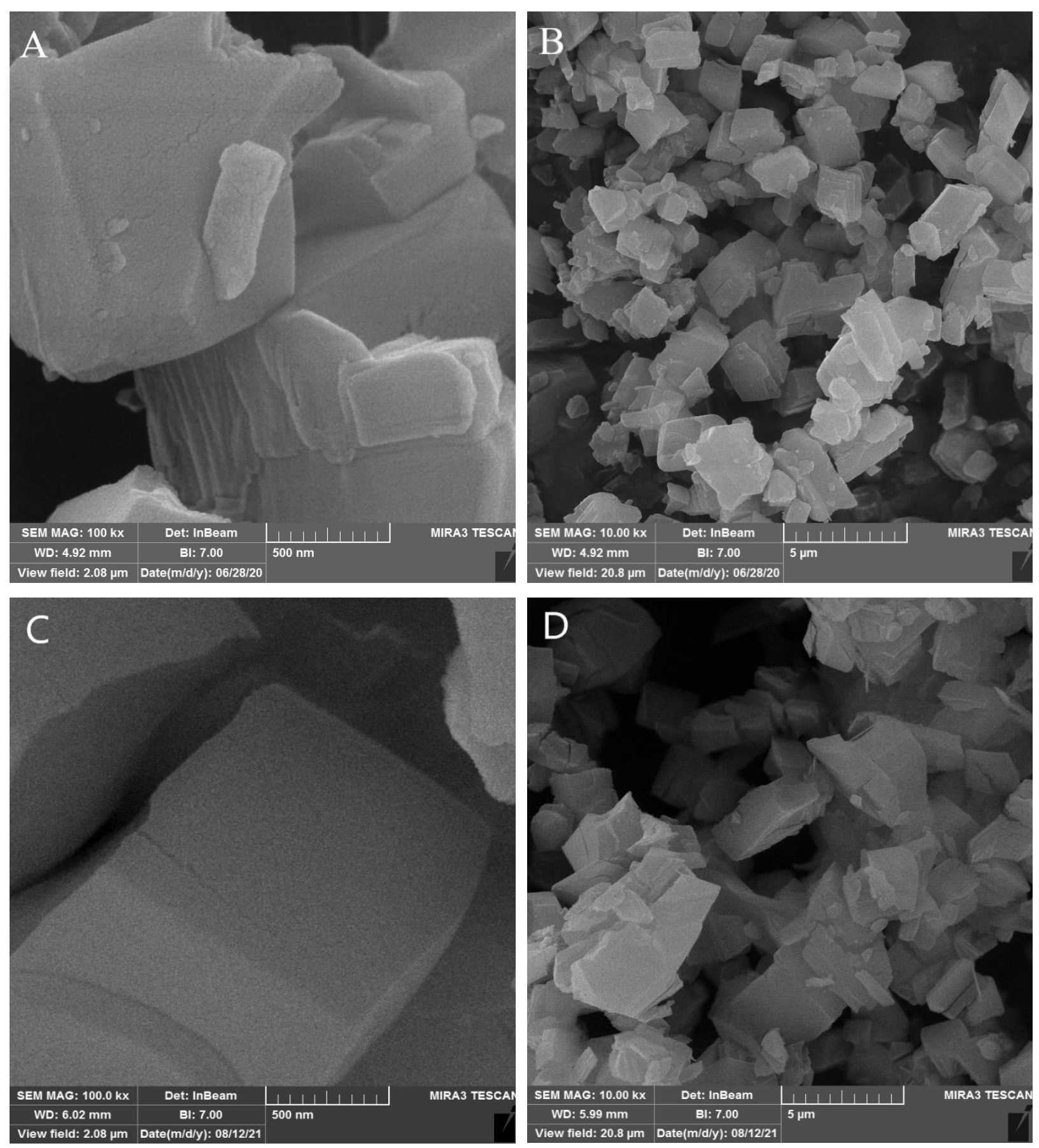

Figure 2. FESEM images of the ultrasonic-assisted and the conventional synthesized MIL-53(Al) at different magnifications.

The N2 adsorption-desorption isotherm of MIL-53(Al) is exhibited in Figure 3. The synthesized sample resembles an IOPAC-type IV isotherm with a type $\mathrm{H} 4$ hysteresis loop, illustrating hierarchical structure including mesoporous and microporous in the sample While conventional synthesis MIL-53(Al) only possesses a microporous structure ${ }^{20}$. Furthermore, BET data of MIL53(Al) are given in Table 1 . The high crystallinity and porosity of the sample yield a high BET 
surface area of $1538.6 \mathrm{~m} 2 / \mathrm{g}$ and a vast average pore size of $1.74 \mathrm{~nm}$. BET surface area and average pore size are greater than those conventionally synthesized MIL-53( $\mathrm{Al})$ introduced in the literature ${ }^{20-22}$; it could be explained by the effect of ultrasound waves on the crystalline structure of MIL-53(Al). Ultrasonic intensity as a driving force ends up in a substantial quantity of cavitation bubbles, and increases in crystallinity, leading to a higher BET expanse in line with the XRD pattern discussed ${ }^{18,23}$. Moreover, the high intensity of ultrasonic waves creates mesopores in the structure of $\mathrm{MOFs}^{24}$, leading to a hierarchical ((meso- and micro-) pores) structures attending to a more significant average pore sizes ${ }^{20,25}$.

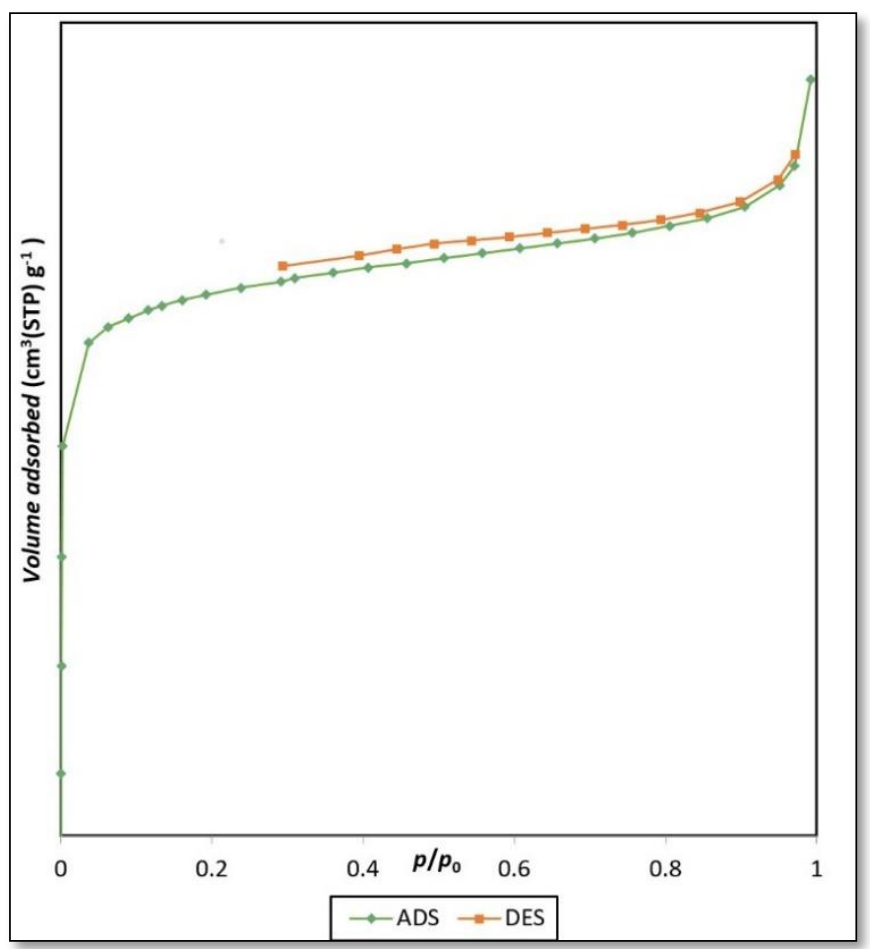

Figure 3. $\mathrm{N}_{2}$ adsorption-desorption isotherm of ultrasonic synthesis MIL-53(Al) 


\begin{tabular}{|c|c|c|c|c|c|c|c|}
\hline Sample & $\begin{array}{c}\text { BET } \\
\text { Surface } \\
\text { area } \\
\left(\mathrm{m}^{2} / \mathrm{g}\right)\end{array}$ & $\begin{array}{c}\text { Pore } \\
\text { volume } \\
\left(\mathrm{cm}^{3} / \mathrm{g}\right)\end{array}$ & $\begin{array}{l}\text { Average } \\
\text { pore } \\
\text { size } \\
(\mathrm{nm})\end{array}$ & $\begin{array}{c}\text { External } \\
\text { surface } \\
\text { area }^{2} \\
\left(\mathrm{~m}^{2} / \mathrm{g}\right)\end{array}$ & $\begin{array}{c}\text { Mesopore } \\
\text { volume } \\
\left(\mathrm{cm}^{2} / \mathrm{g}\right)\end{array}$ & $\begin{array}{l}\text { Micropore } \\
\text { volume } \\
\left(\mathrm{cm}^{2} / \mathrm{g}\right)\end{array}$ & Ref. \\
\hline $\begin{array}{l}\text { UAS MIL- } \\
\text { 53(Al) }\end{array}$ & 1538.6 & 0.671 & 1.7443 & 20.22 & 0.07 & 0.600 & $\begin{array}{l}\text { This } \\
\text { study }\end{array}$ \\
\hline CS MIL-53(Al) & 1274.3 & 0.560 & 1.755 & 5.88 & 0.027 & 0.533 & $\begin{array}{l}\text { This } \\
\text { study }\end{array}$ \\
\hline MIL-53(Al) & 1184 & - & - & - & 0 & 0.45 & 20 \\
\hline MIL-53(Al) & 1073 & 0.46 & - & - & - & - & 21 \\
\hline MIL-53(Al) & 1027 & 0.56 & 0.66 & - & - & - & 22 \\
\hline
\end{tabular}

Table 1. BET characteristics of MIL-53(Al).

${ }^{1}$ Measured using t-plot method.

${ }^{2}$ Measured using t-plot method.

${ }^{3}$ Mesopore volume(From BJH model) = Totalpore volume- Micropore volume.

Figure 4 illustrates the FT-IR spectrum of the synthesized UAS MIL-53(Al) which also shows the vibration bands in the wavelength range of $1700-1400 \mathrm{~cm}^{-1}$, indicating that the carboxylic functional groups are attached to aluminum. According to this figure, the firm observed peaks at 1507.87 and $1579.56 \mathrm{~cm}^{-1}$ belong to the (-COO) asymmetric stretching, and the characteristic peak at 1413.15 belongs to ( $-\mathrm{COO})$ symmetric stretching of the carboxyl vibration. No additional peak is observed at a wavenumber of $1700 \mathrm{~cm}^{-1}$, indicating that the free BDC acid molecules are completely removed from UAS MIL-53(Al) pores ${ }^{17}$. The peaks at $1631.9 \mathrm{~cm}^{-1}$ and vibration bands ranging from $3700 \pm 3400 \mathrm{~cm}-1$ confirm the observation of the bending and stretching modes of water as well as the signature of the hydroxyl group that links the aluminum particles ${ }^{26}$. The FTIR bands were considerably similar to the FTIR of US MIL-53(Al) samples from the standard MIL-53(Al) ${ }^{26}$. 


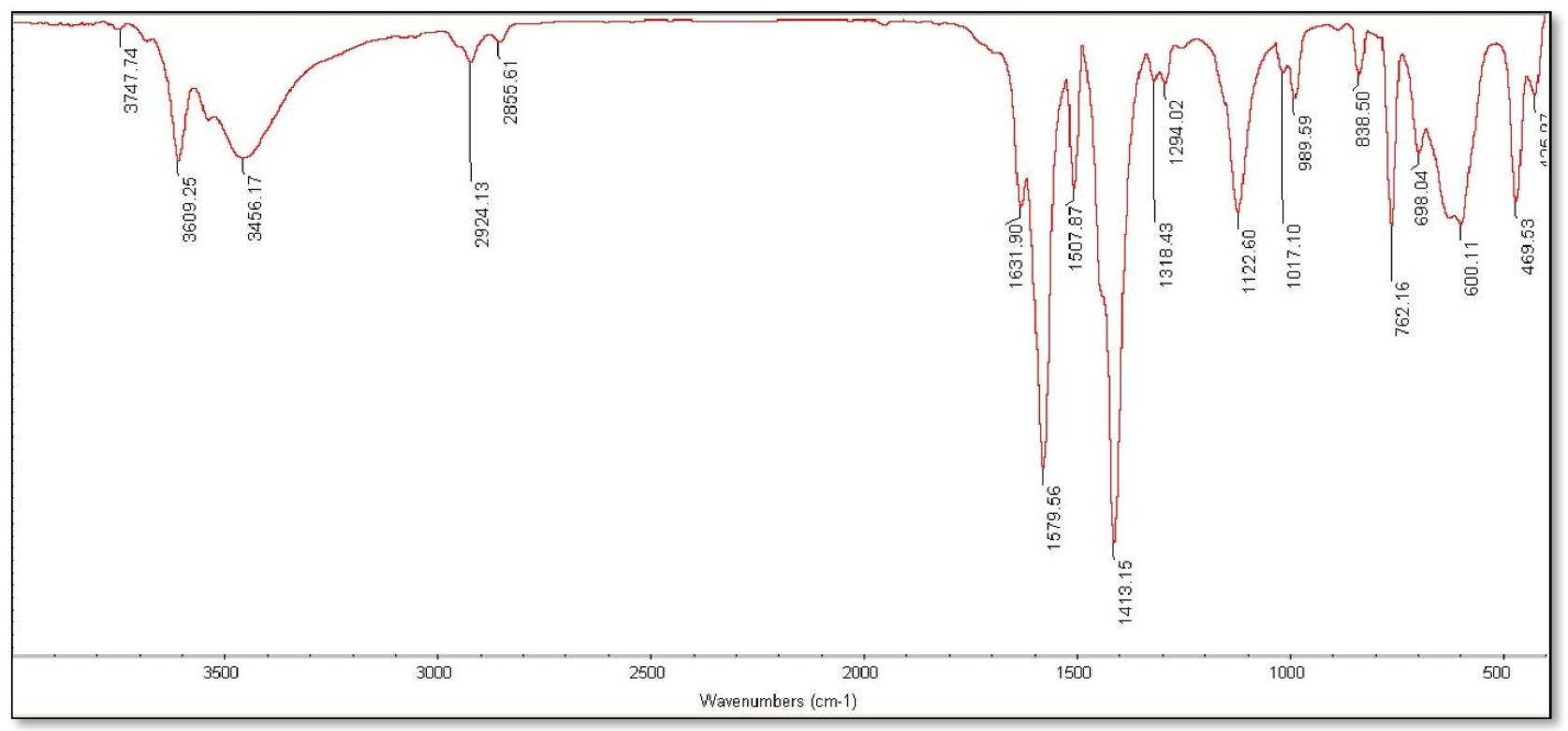

Figure 4. FT-IR spectrum of MIL-53(AI).

\section{Adsorption parameters efficiency studies}

\section{Selectivity of nickel, copper, lead on US MIL-53(AI)}

In order to discover the selectivity of UAS MIL-53(Al) in removing the heavy metals from water, an adsorption experiment was carried out to measure the remaining concentration of these metals such as $\mathrm{pb}^{2+}, \mathrm{Ni}^{2+}, \mathrm{Cu}^{2+}$ in the solution after adsorption. Three adsorption experiments, each containing $20 \mathrm{ppm}$ of intended heavy metal, $0.03 \mathrm{~g}$ US MIL-53(Al), and $40 \mathrm{ml}$ solution, were carried out to determine the selectivity of the adsorbent. According to the Figure 5, MIL-53(Al) as an adsorbent can perfectly remove lead from the solution since it comprises carbonyl groups. Therefore, the following tests were carried out using lead only. 


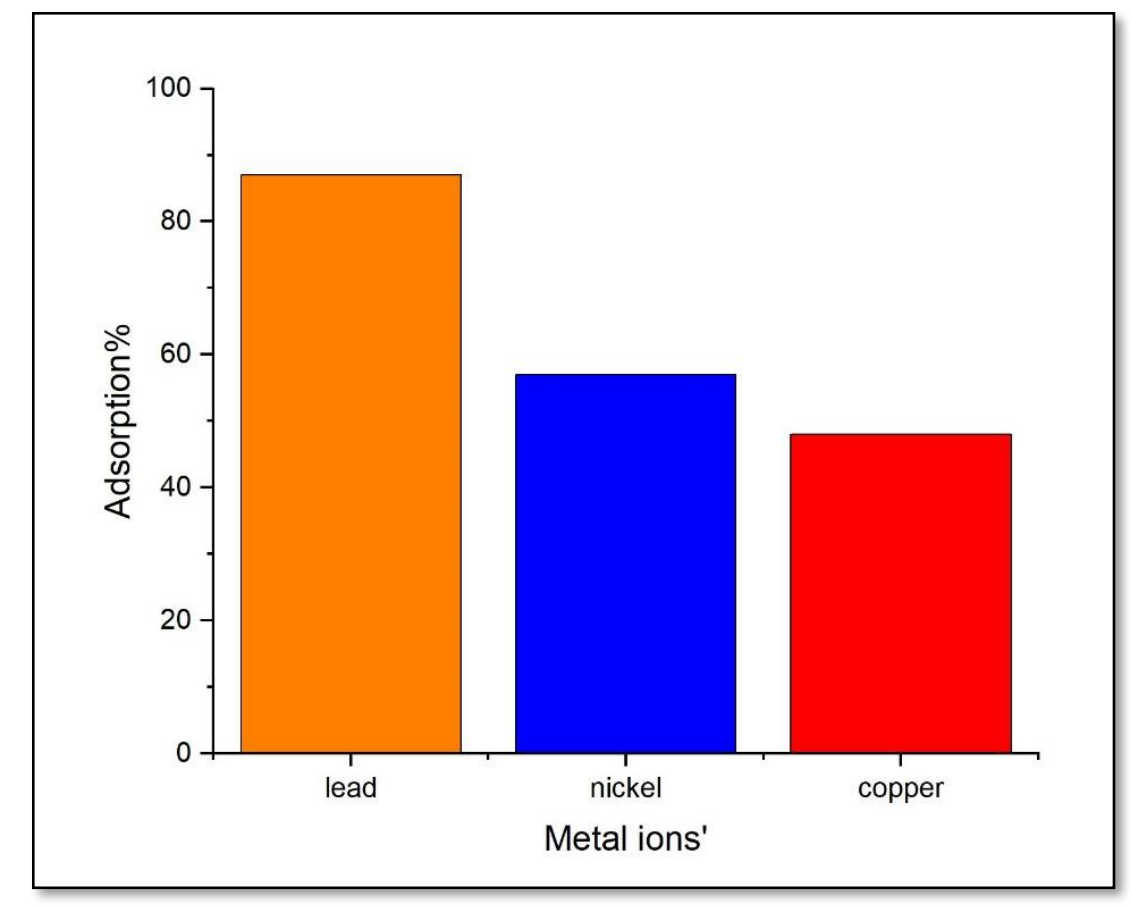

Figure 5. US MIL-53(Al) selectivity of heavy metal ion's

(20 ppm of intended heavy metal, $0.03 \mathrm{~g} \mathrm{MIL-53(Al),} \mathrm{and} 40 \mathrm{ml}$ solution, 298K temperature)

\section{Effect of pH on adsorption rate}

The $\mathrm{pH}$ of the mixture is considered an essential parameter to be examined during the adsorption studies since changing $\mathrm{pH}$ can alter the surface charge of the adsorbent. Also, $\mathrm{pH}$ can strongly influence the solubility of metal ion. ${ }^{27}$. First, in order to choose the $\mathrm{pH}$ range of the solution, the pHpzc of the adsorbent should be analyzed. The $\mathrm{pH}_{\mathrm{pzc}}$ of the solution is at which the surface charge of the adsorbent is zero. In case $\mathrm{pH}_{\mathrm{pzc}}>\mathrm{pH}$, the surface has a more positive charge by decreasing $\mathrm{pH}$, and in case $\mathrm{pH}_{\mathrm{pzc}}<\mathrm{pH}$, the surface has a more negative charge by increasing the $\mathrm{pH}$. Figure 6 shows the $\mathrm{pH}_{\mathrm{pzc}}$ in this study. The removal efficiency of $\mathrm{Pb}(\mathrm{II})$ ions was investigated in different initial $\mathrm{pH}$ ranges ( 2.0 to 7.0), as shown in Figure 7, which were set using the required amount of $\mathrm{HCl}$ or $\mathrm{NaOH}$ solutions. The $\mathrm{pH}$ range in this study was selected from ( 2.0 to 7.0 ) because at $\mathrm{pH}$ $\geq 7$, lead ions precipitated as $\mathrm{Pb}(\mathrm{OH})_{2}$. While $\mathrm{pH}_{\mathrm{pzc}}$ 's adsorbent charge, at $\mathrm{pH}$ above 5 is negative, it is positive at lower $\mathrm{pH}^{12,28,29}$. As observed in Figure 7, upon increasing the $\mathrm{pH}$ from 2 to 7, at first, the removal of adsorption on UAS MIL-53(Al) increases from $19 \%$ to $86 \%$, meaning that the surface charge of adsorbent is negative. Then $\mathrm{pH}$ of 7 causes $\mathrm{Pb}$ (II) to hydrolyze in aqueous solution resulting in a slight decrease in adsorption rate. Finally, the optimum $\mathrm{pH}$ is obtained at 
6.0. Therefore, as $\mathrm{pH}$ increases, the attraction between $\mathrm{Pb}^{2+}$ and the opposing surface increases. As a result, the adsorption rate of lead ions increases upon reducing hydrogen ion concentration which competes with $\mathrm{Pb}^{2+}$ ions for the adsorbent sites. The additional parameters to be considered include initial $\mathrm{Pb}(\mathrm{II})$ concentration $(20.0 \mathrm{ppm})$, contact time (60.0 $\mathrm{min})$, volume of the solution (40 $\mathrm{ml}$ ), adsorbent dosage of $0.04 \mathrm{~g}$, and temperature of $298 \mathrm{~K}$.

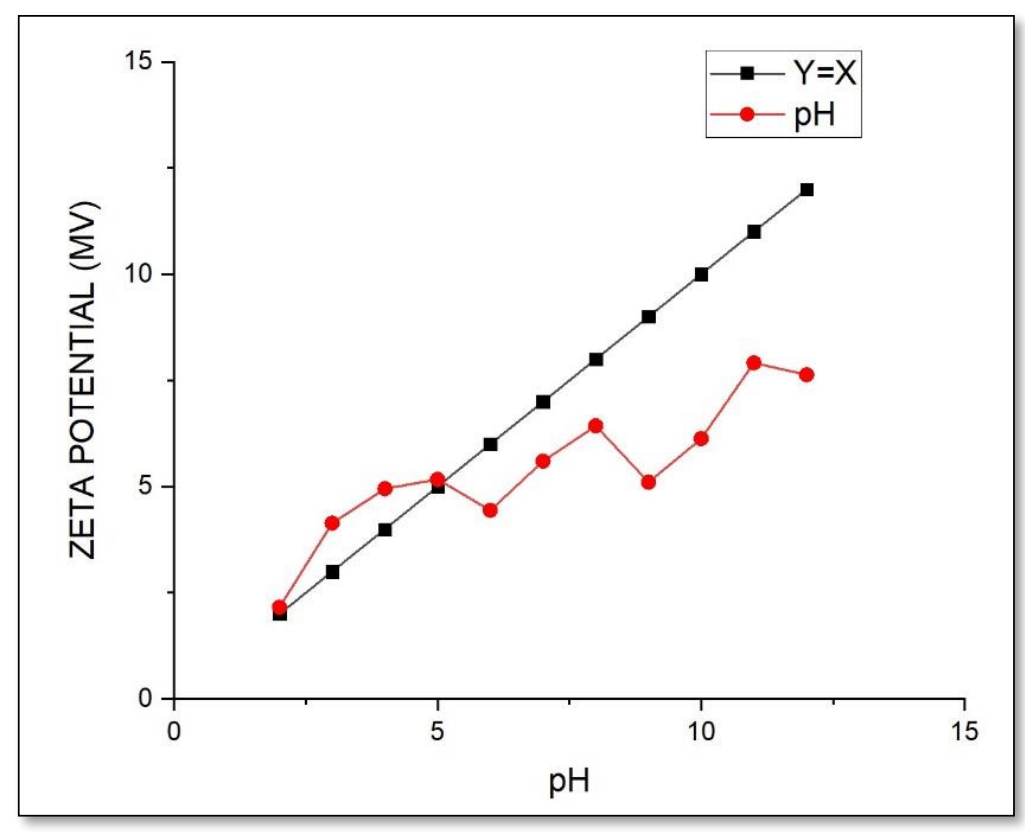

Figure 6. Effect of $\mathrm{pH}$ on the zeta potential of US MIL-53(Al) adsorbent 


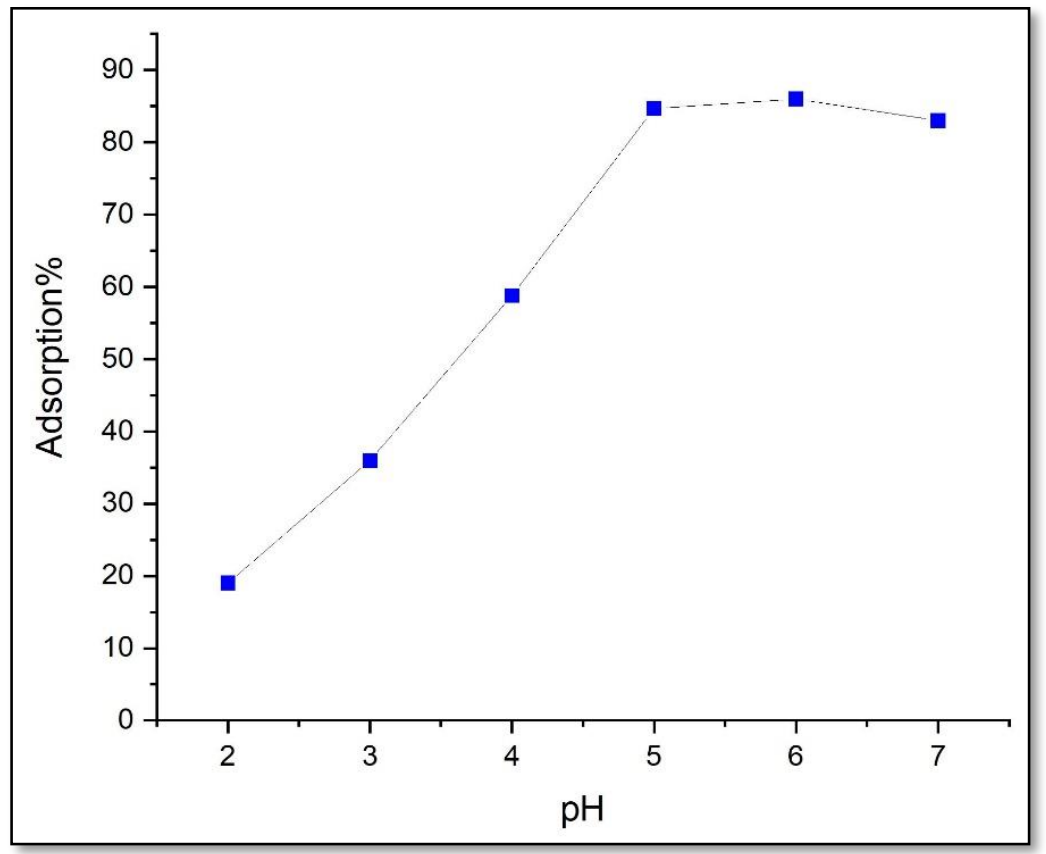

Figure 7.Effect of $\mathrm{pH}$

(pH range (2-7), $\mathrm{Pb}(\mathrm{II})$ concentration (20.0 ppm), contact time (60.0 min), volume of the solution (40 ml), adsorbent dosage of $0.04 \mathrm{~g}$, and temperature of $298 \mathrm{~K}$ )

\section{Effect of adsorption dosage}

The effect of UAS MIL-53(Al) dosage on Pb removal was studied in the range of 0.001 to $0.04 \mathrm{~g}$. This study was conducted at a temperature of $298 \mathrm{~K}$ and $\mathrm{pH}$ of 6 with an initial $\mathrm{Pb}$ (II) concentration of $20 \mathrm{ppm}$ for about 60 minutes. As shown in Figure 8, the adsorption rate of $\mathrm{Pb}$ (II) increases from $27.1 \%$ to $86 \%$ upon increasing UAS MIL-53(Al) dose, thus increasing the number of available adsorption sites on the UAS MIL-53(Al) surface for binding $\mathrm{Pb}$ (II) ions. The significance of the adsorbent dosage indicates its adsorption capacity at a specific initial concentration. It is expected that upon increasing the amount of the adsorbent, the adsorption efficiency will increase due to the increasing amount of adsorbent. Because of the large surface area of the sample, the number of active sites for complexing metal ions increases and the adsorption process accelerates ${ }^{30}$. In case the adsorbent reaches its maximum efficiency, the number of active sites on the adsorbent surface corresponds to the number of metal ions available in the solution in the equilibrium adsorption process. 


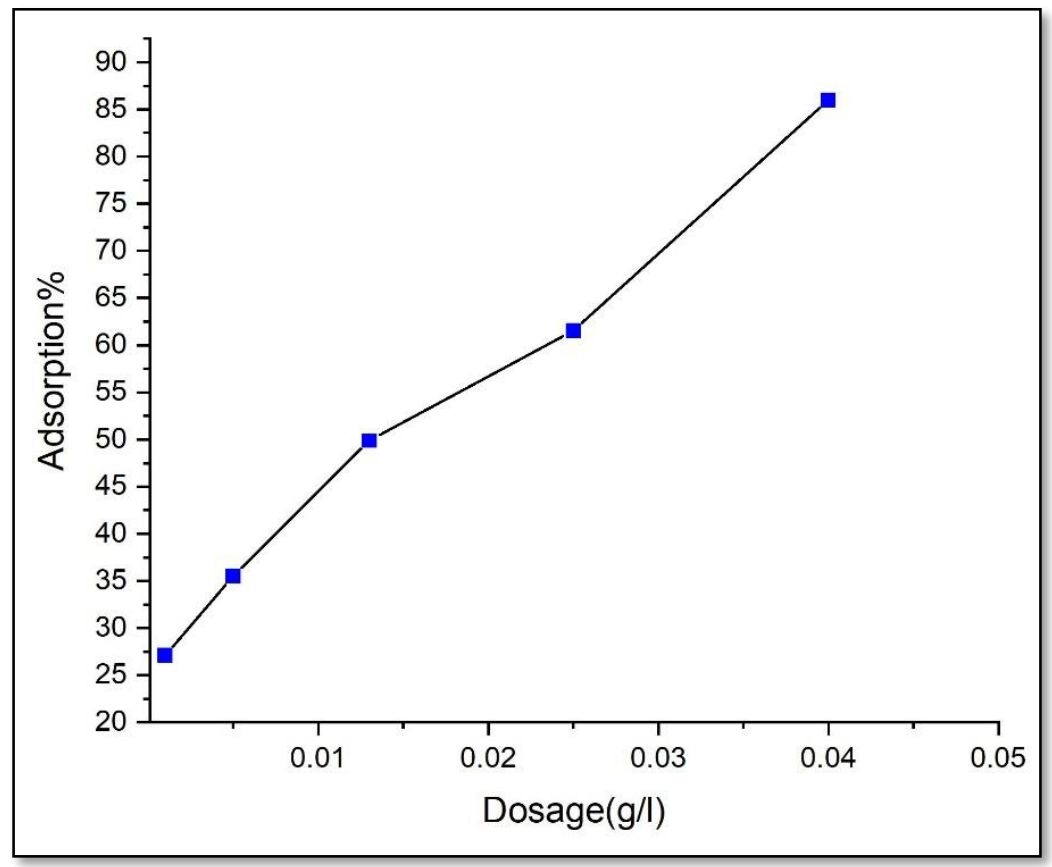

Figure 8. Effect of adsorbent dosage.

(pH of 6, Pb(II) concentration (20.0 ppm), contact time (60.0 min), volume of the solution (40 ml), adsorbent dosage range of (0.001 to $0.04 \mathrm{~g}$ ), and temperature of $298 \mathrm{~K}$ )

\section{Effect of initial concentration}

The effect of the initial concentration of UAS MIL-53(Al) on the adsorption of $\mathrm{Pb}$ was examined in the range of 20.0-130.0 ppm at a temperature of $298 \mathrm{~K}$ and $\mathrm{pH}$ of 6. As shown in Figure 9, as the initial concentration of lead ions increases, the removal percentage for this ion decreases from $86 \%$ to $34.5 \%$, mainly because the interaction between lead ions and the active adsorbent sites increases at low concentrations, thus leading to a high percentage of adsorption. However, due to the saturation of the adsorbent surface at higher concentrations, more metal ions remain unabsorbed in the solution and the adsorption efficiency decreases upon increasing the concentration. An increase in the concentration of the metal ion would increase the number of collisions between the metal ions and the adsorbent, stimulating the removal of the heavy metal. The number of adsorbed metal ions per adsorbent mass increases in this process. In addition, the adsorption capacity increases as a result of increasing the initial concentrations of metal ions in the solution. 


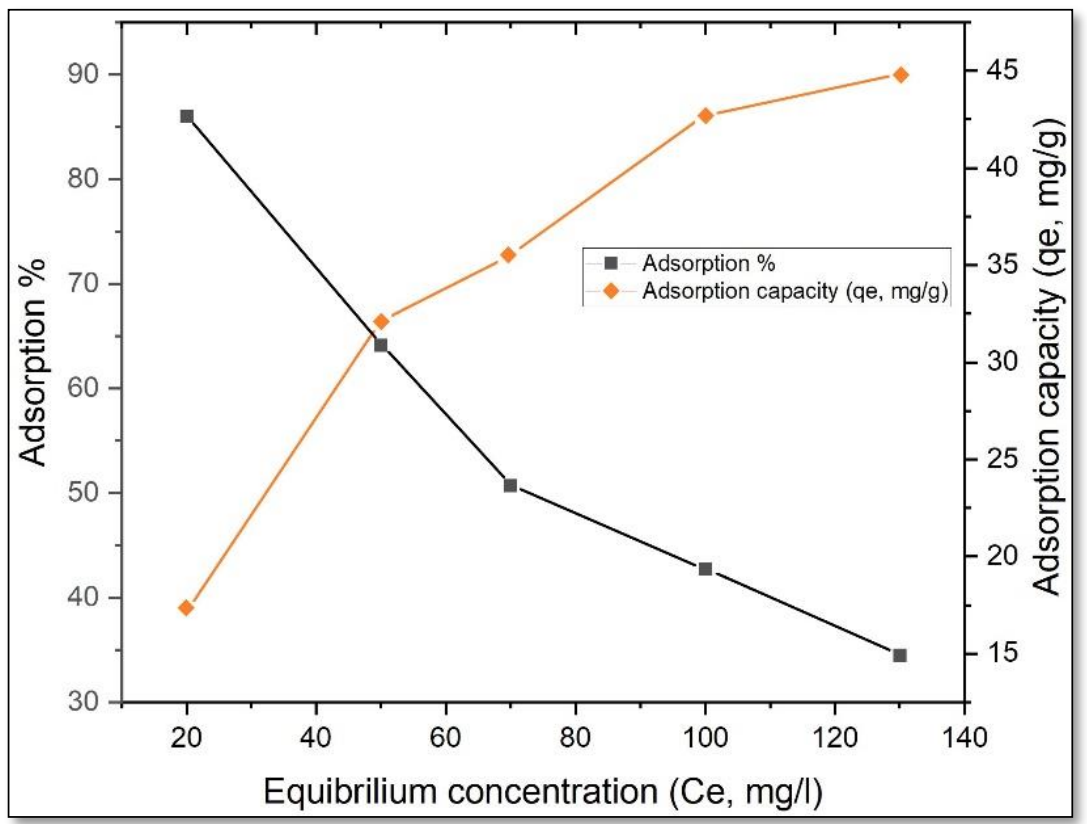

Figure 9. Effect of initial concentration

(pH of 6, Pb(II) concentration range of (20.0-130.0 ppm), contact time (60.0 min), volume of the solution (40 ml), adsorbent dosage (0.04g), and temperature of $298 \mathrm{~K})$

\section{Effect of temperature on adsorption rate}

The adsorption rate of lead ions via UAS MIL-53(Al) was investigated in a condition characterized by an initial $\mathrm{Pb}(\mathrm{II})$ concentration of $20 \mathrm{ppm}, \mathrm{pH}$ of $6,0.04 \mathrm{~g}$ of the adsorbent, and varying temperatures of 288, 298, 308, and $318 \mathrm{~K}$. Figure 10 shows a comparison between the removal efficiency and temperature, depicting an increase in the amount of the adsorption while increasing temperature from $66.9 \%$ to $97.63 \%$ mainly due to the movement of lead ions and the consequent increase in the number of ions colliding with active sites. In addition, increasing the temperature can reduce the viscosity of the solution, which ultimately increases the penetration rate of the adsorbent molecule, hence an increase in the amount of the adsorption. 


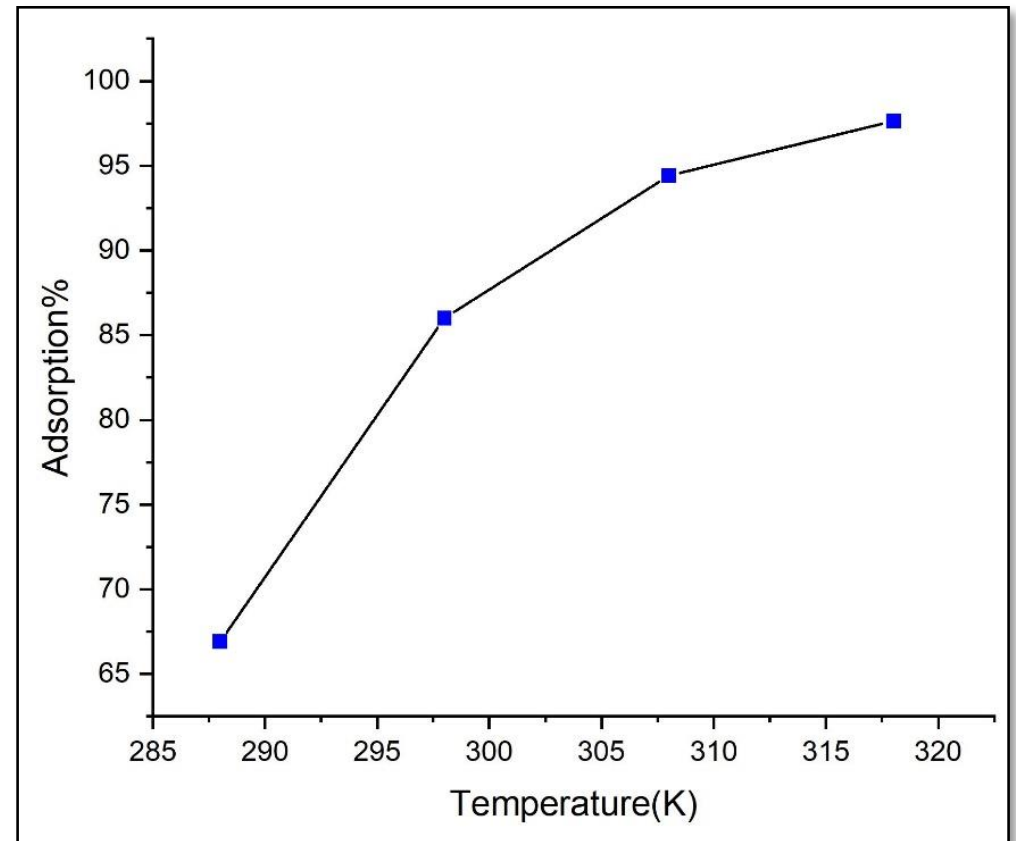

Figure 10. Effect of temperature

(pH of 6, Pb(II) concentration (20.0 ppm), contact time (60.0 min), volume of the solution (40 ml), adsorbent dosage (0.04g), and temperature range of $(288 \mathrm{~K}-318 \mathrm{~K}))$

\section{Effect of contact time on adsorption rate}

The effect of contact time on the adsorption rate of lead was investigated using $0.04 \mathrm{~g}$ UAS MIL-53 (Al) as an adsorbent in different time durations from 5 to 180 minutes under some other conditions such as initial $\mathrm{Pb}$ (II) concentration of $20 \mathrm{ppm}, \mathrm{pH}$ of 6, and temperature of $298 \mathrm{~K}$. As observed in Figure 11, the adsorption percentage increases upon increasing the time. Finally, by occupying all the active sites on the adsorbent, the adsorption speed would decrease until reaching equilibrium. The changes occur rapidly in the first 30 minutes and the adsorption capacity increases fast. Then, its growth rate decreases considerably and reaches equilibrium in 60 minutes. Hence, the time limit decreases from $180 \mathrm{~min}$ to $60 \mathrm{~min}$ for all the other experiments. During the first 30 minutes of the adsorption, the process accelerates owing to the large number of adsorption sites available for metal ions. Over time, increased adsorption slows down due to such constraints as repulsive forces between the adsorbed metal ions on the surface of UAS MIL-53(Al) and metal ions in the liquid; of note, the adsorption sites remain intact. On the contrary, during the initial stages of adsorption, the adsorbent pores are filled by the adsorbed ions. In the latter stages of adsorption, 
the metal ions are forced to move more profoundly and longer to capture the pores, thus reducing the adsorption rate within minutes. The adsorption process continues until reaching the equilibrium time for adsorption. Equilibrium time is defined as when the adsorption process reaches equilibrium and saturation and the adsorption rate does not change much with time.

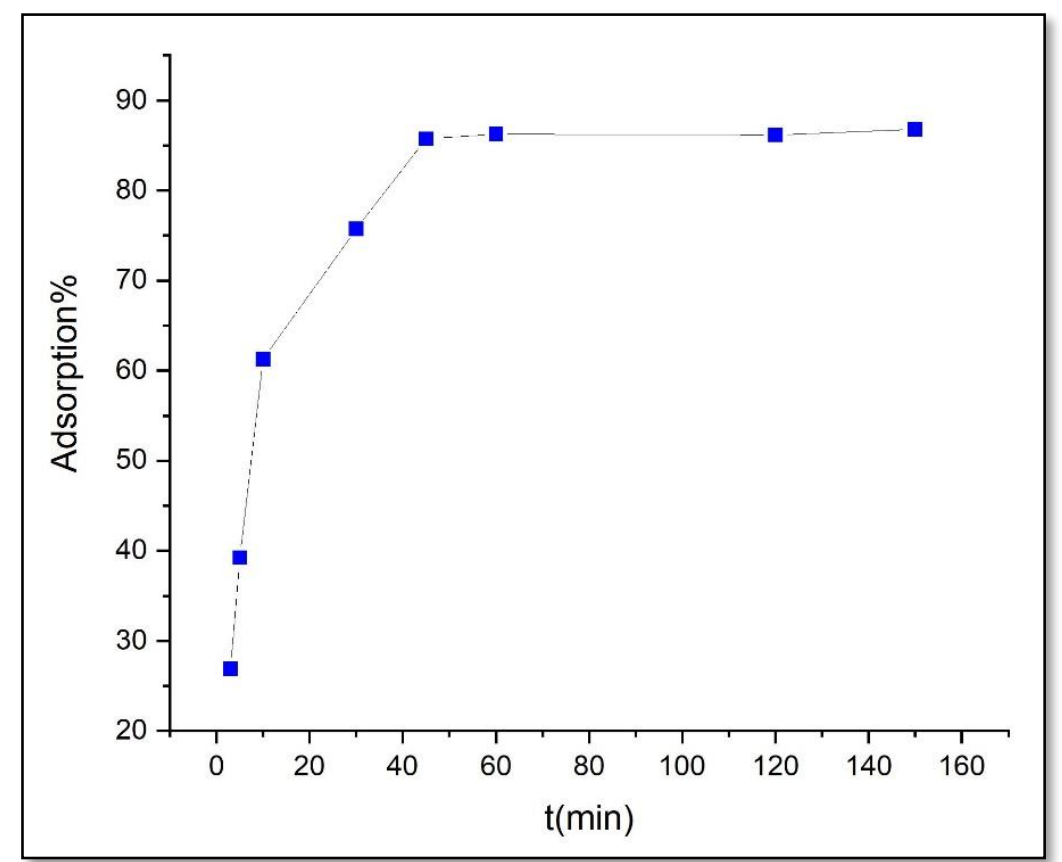

Figure 11. Effect of time

( $\mathrm{pH}$ of 6, $\mathrm{Pb}$ (II) concentration (20.0 ppm), contact time range of (5.0-180.0 min), volume of the solution (40 ml), adsorbent dosage (0.04g), and temperature of $298 \mathrm{~K})$ )

\section{Adsorption isotherm}

The adsorption isotherm models proposed by Langmuir ${ }^{31}$, Freundlich $^{31}$, Temkin $^{31}$ were applied at a temperature of $298 \mathrm{~K}$ with different lead concentrations of 20, 50, 70, 100, and $130 \mathrm{ppm}, 0.04 \mathrm{~g}$ of UAS MIL-53(Al), and $\mathrm{pH}$ of 6 for 60 min to investigate the interaction between equilibrium concentration data and lead ion adsorption.

\section{Langmuir isotherm}

This isotherm is employed to adsorb a dynamic equilibrium surface on perfectly homogeneous surfaces, assuming a monolayer coating onto the adsorbent surface area. In addition, due to the 
occupation of the adsorption sites, the adsorbed molecules do not interact with each other. The parameters of the Langmuir isotherm can be calculated through plotting its linear diagram in equation (3), as shown in the following:

$$
\frac{c_{e}}{q_{e}}=c_{e} \frac{1}{q_{m}}+\frac{1}{k_{l} q_{m}}
$$

where $\mathrm{C}_{\mathrm{e}}(\mathrm{mg} / \mathrm{l})$ is the metal ion concentration, $\mathrm{q}_{\mathrm{e}}(\mathrm{mg} / \mathrm{g})$ the number of metal ions adsorbed in the equilibrium phase, $\mathrm{q}_{\mathrm{m}}$ the maximum monolayer adsorption $(\mathrm{mg} / \mathrm{g})$, and $\mathrm{k}_{\mathrm{l}}(\mathrm{L} / \mathrm{mg})$ the Langmuir constant related to the adsorption energy. The values for the Langmuir constants $\mathrm{k}_{1}$ and $\mathrm{q}_{\mathrm{m}}$ were achieved from slope and intercept of $\mathrm{C}_{\mathrm{e}} \mathrm{vs} . \mathrm{C}_{\mathrm{e}} / \mathrm{q}_{\mathrm{e}}$ plot given in Table 2 \& Figure 12. In case $\mathrm{R}^{2}$ is more than 0.99, the surface assimilation of the method follows the Langmuir isotherm. The dimensionless equilibrium parameter $R_{L}$ is defined to explain the type of isotherm (if $R_{L}=0$, irreversible; $\mathrm{R}_{\mathrm{L}}>1$, unfavorable; $0<\mathrm{R}_{\mathrm{L}}<1$, favorable; and $\mathrm{R}_{\mathrm{L}}=1$, linear) in the adsorption process obtained from equation(4). ${ }^{32}$.

$$
R_{l}=\frac{1}{1+K_{l} C_{0}}
$$

where $\mathrm{C}_{0}$ is the initial concentration $(\mathrm{mg} / \mathrm{l})$. In case the value of $\mathrm{R}^{2}$ is 0.9965 , the Langmuir isotherm fits the adsorption data and since $0<R_{L}<1$, the type of Langmuir isotherm is favorable. The maximum monolayer adsorption $\left(\mathrm{q}_{\mathrm{m}}\right)$ can be achieved by linear Langmuir isotherm that is estimated to be $48.076 \mathrm{mg} / \mathrm{g}$ near the values of experimental maximum adsorption capacity (44.85 $\mathrm{mg} / \mathrm{g})$.

\section{Freundlich isotherm}

Freundlich equilibrium isotherm model can illustrate the concept of heterogeneous surfaces and assume adsorption on the multilayer surfaces. The parameters of this model $\left(\mathrm{k}_{\mathrm{f}}\right.$ and $\left.\mathrm{n}\right)$ can be calculated from the intercept and slope of $\ln \mathrm{q}_{\mathrm{e}} \mathrm{vs}$. $\ln \mathrm{C}_{\mathrm{e}}$ diagram, respectively, using equation (5).

$$
\ln q_{e}=\ln K_{f}+\frac{1}{n}\left(\ln C_{e}\right)
$$


where $\mathrm{K}_{\mathrm{f}}$ is an adsorption isotherm constant that signifies an approximate adsorption capacity and $\mathrm{n}$ is the Freundlich equilibrium constant related to the adsorption intensity. If the value of $\mathrm{n}$ ranges from one to ten, the adsorption is assumed favorable. In the case of $n=3.6941$, the adsorption process is favorable. The values of Freundlich constants are given in Table 2 and Figure 12.

\section{Temkin isotherm}

Temkin isotherm is elaborated in equations (6) and (7). Through this model, the effect of the indirect interaction of adsorbent on the heat reduction of the adsorption can be clarified ${ }^{33}$.

$$
\begin{gathered}
q_{e}=B_{T} \ln A_{T}+B_{T} \ln C_{e} \\
q_{e}=\frac{R T}{B_{T}} \ln K_{T}+\frac{R T}{B_{T}} \ln C_{e}
\end{gathered}
$$

$\mathrm{B}_{\mathrm{T}}(\mathrm{J} / \mathrm{mol})$ constant denotes the heat of the adsorption coverage, and $\mathrm{K}_{\mathrm{T}}(\mathrm{L} / \mathrm{g})$ is a constant of the binding energy, indicating the significant connection between the adsorbate and adsorbent ${ }^{33}$. Moreover, the Temkin isotherm $\left(\mathrm{K}_{\mathrm{T}}\right.$ and $\left.\mathrm{B}_{\mathrm{T}}\right)$ constants can be measured by plotting $\ln \mathrm{q}_{\mathrm{e}}$ vs. $\ln \mathrm{C}_{\mathrm{e}}$ diagram from the intercept and slope, respectively. The isotherm model plots are given in Figure 12, and all the constant values are summarized in Table 2.
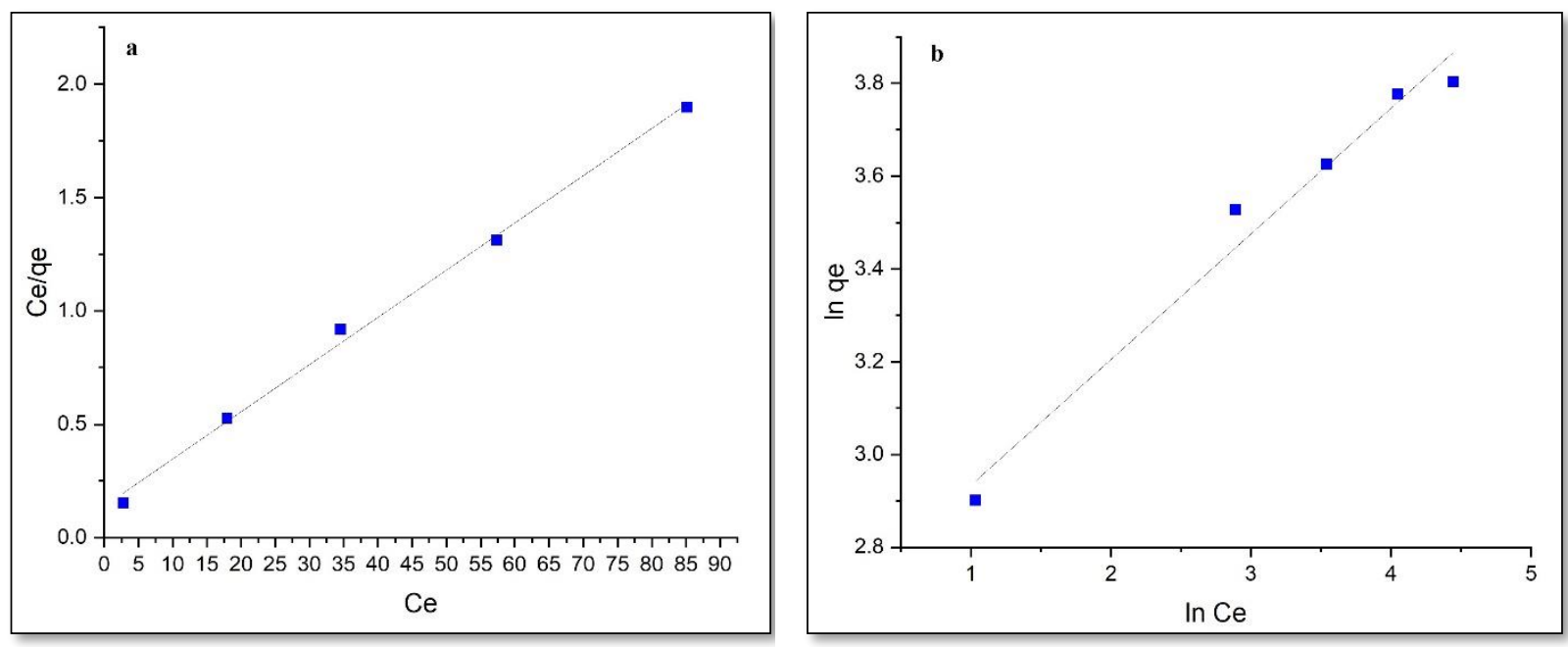


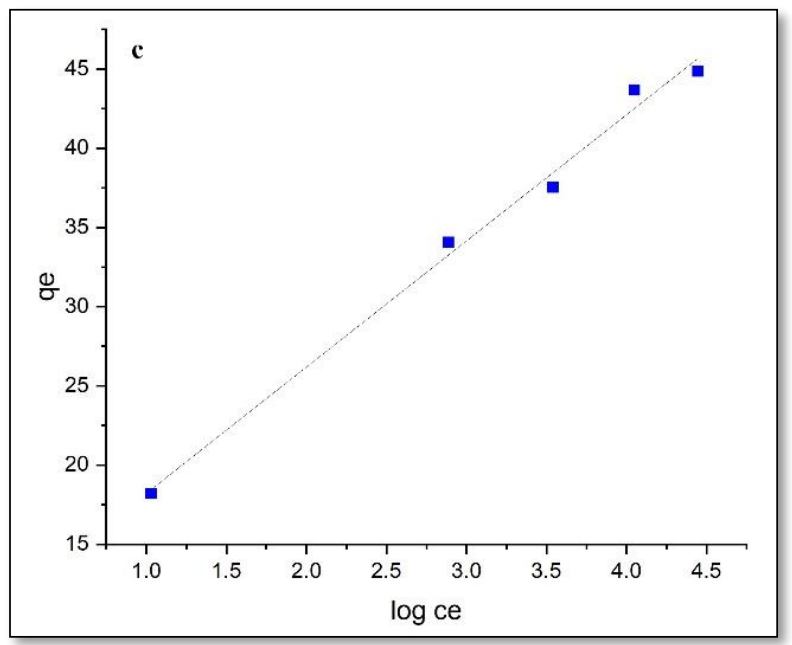

Figure 12. $a$. the Langmuir, b. the Freundlich, and c. the Temkin isotherms.

(( $\mathrm{pH}$ of 6, $\mathrm{Pb}$ (II) concentration range of (20-130 ppm), contact time $(60.0 \mathrm{~min})$, volume of the solution (40 ml), adsorbent dosage of $(0.04 \mathrm{~g})$, and temperature of $(298 \mathrm{~K}))$

\begin{tabular}{clc}
\hline Isotherm models & Parameters & Adsorption of lead on MIL-53(Al) \\
\hline \multirow{2}{*}{ Langmuir } & Temp & $298 \mathrm{~K}$ \\
& $\mathrm{q}_{\mathrm{m}}(\mathrm{mg} / \mathrm{g})$ & 48.076 \\
& $\mathrm{~K}_{\mathrm{L}}(\mathrm{l} / \mathrm{mg})$ & 0.149 \\
& $\mathrm{R}^{2}$ & 0.9965 \\
& $\mathrm{R}_{\mathrm{L}}$ & 0.049 \\
Freundlich & $\mathrm{Temp}$ & $298 \mathrm{~K}$ \\
& $\mathrm{~K}_{\mathrm{f}}$ & 14.34 \\
& $\mathrm{n}$ & 3.6941 \\
& $\mathrm{R}^{2}$ & 0.9763 \\
& $\mathrm{Temp}$ & $298 \mathrm{~K}$ \\
& $\mathrm{~K}_{\mathrm{T}}(\mathrm{L} / \mathrm{g})$ & 3.9226 \\
& $\mathrm{~B}_{\mathrm{T}}(\mathrm{J} / \mathrm{mol})$ & 9.7037 \\
& $\mathrm{R}^{2}$ & 0.9712 \\
\hline
\end{tabular}

Table 2. isotherm parameters values of Langmuir, Freundlich, Temkin models for the adsorption of pb(II) on US MIL-53(AI). 


\section{Adsorption Kinetic}

The kinetic studies were conducted using $0.04 \mathrm{~g}$ of UAS MIL-53 (Al) as an adsorbent in the condition characterized by different times (5.0-180.0 min), $\mathrm{pH}$ of 6.0, and temperature of $298 \mathrm{~K}$ using $20 \mathrm{ppm}$ of the initial concentration to remove lead ion from $40 \mathrm{ml}$ solution. Kinetic models were taken into account to determine the effect of contact time on the adsorption rate and present valuable information about the process mechanism, equilibrium time, and rate control levels. The kinetic models employed to analyze the data and evaluate the adsorption quality included pseudofirst-order and pseudo-second-order as well as intra-particle diffusion kinetic models ${ }^{34}$. Kinetic results are summarized in Table 3.

\section{Pseudo first-order kinetic reaction}

The Pseudo first-order rate is presented in equation $(8)^{35}$.

$$
\ln \left(q_{e}-q_{t}\right)=\ln q_{e}-k_{1} t
$$

in which $\mathrm{q}_{\mathrm{e}}(\mathrm{mg} / \mathrm{g})$ is the equilibrium concentration, $\mathrm{q}_{\mathrm{t}}(\mathrm{mg} / \mathrm{g})$ the concentration an any time, and

$\mathrm{K}_{1}\left(\mathrm{~min}^{-1}\right)$ a pseudo-first-order rate constant. The $\mathrm{k}_{1}$ and $\ln \mathrm{q}_{\mathrm{e}}$ of the pseudo-first-order model can be obtained from the slope and intercept of $\ln \left(\mathrm{q}_{\mathrm{e}}-\mathrm{q}_{\mathrm{t}}\right) \mathrm{vs}$. time plot.

\section{Pseudo-second order kinetic reaction}

The pseudo-second-order rate is determined using equation (9) ${ }^{34}$.

$$
\frac{t}{q_{t}}=\frac{1}{q_{e}^{2} K_{2}}+\frac{t}{q_{e}}
$$

in which $\mathrm{K}_{2}$ (g/g.min) is a pseudo-second-order constant. The $\mathrm{k}_{2}$ and $\mathrm{q}_{\mathrm{e}}$ of the pseudo-secondorder model can be obtained by plotting the $t / q_{t}$ vs. time diagram. In this case, the values of $1 / q_{e}$ and $1 / \mathrm{k}_{2} \cdot \mathrm{qe}^{2}$ can be obtained from the slope and intercept, respectively.

Table 3 presents the kinetic data at $\mathrm{C}_{0}: 20 \mathrm{ppm}$ achieved based on their plots. The $\mathrm{R}^{2}$ values for the pseudo-first-order and pseudo-second-order kinetic models were 0.8547 and 0.9975 , respectively. Due to the higher value of the pseudo-second-order $\mathrm{R}^{2}$, a better fit for kinetic data was found. Moreover, theoretical values of $\mathrm{q}_{\mathrm{e}}$ from the pseudo-first-order rate and pseudo-second-order rate were $10.26 \mathrm{mg} / \mathrm{g}$ and $18.51 \mathrm{mg} / \mathrm{g}$, respectively. Furthermore, the experimental $\mathrm{q}$ was found 
at $17.35 \mathrm{mg} / \mathrm{g}$. In the comparison, the consistency between the experimental and theoretical data also confirmed that the pseudo-second-order kinetic model described the adsorption process better, which illustrated that the adsorption rate and the active sites of the adsorbent were comparable.

\section{Intra-Particle Diffusion kinetic reaction}

Equation (10) defines the intraparticle diffusion rate to detect the diffusion mechanism and rate control steps of the adsorption process ${ }^{36}$.

$$
q_{t}=K_{i} t^{0 / 5}+c
$$

in which $\mathrm{K}_{\mathrm{i}}$ is the intraparticle diffusion rate constant (mg/g.min1/2) and $\mathrm{C}(\mathrm{mg} / \mathrm{g}$ ) (Table 3). Intraparticulate diffusion predominantly contributes to the rate-limiting step if the correlation diagram of adsorbed ions $\left(\mathrm{q}_{\mathrm{t}}\right)$ vs. $\left(\mathrm{t}^{0.5}\right)$ gives a straight line through the origin. A dual linear nature is given in Figure 13 based on linear proportion including initial and final stages. The high values of $\mathrm{R}^{2}$ of the initial stage indicate that the adsorption follows diffusions with the particles or mass transfer. In contrast, another stage involves other adsorption processes that may overcome the challenges of adsorption mechanism.
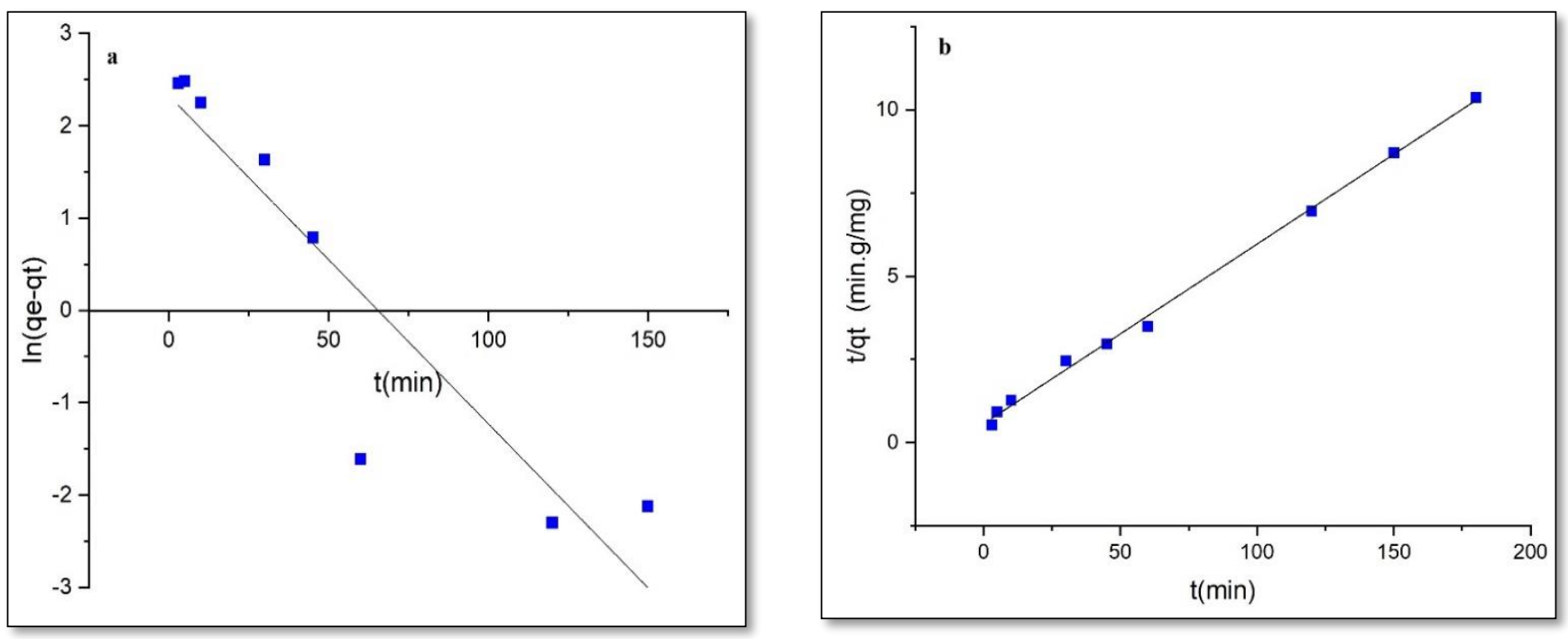


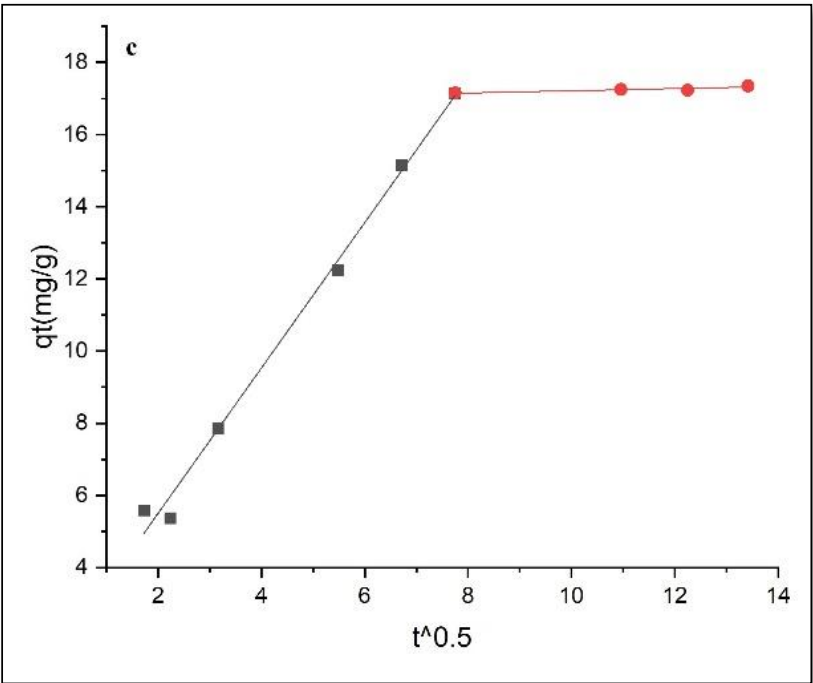

Figure 13.(a) pseudo first-order kinetic, (b) pseudo second-order kinetic, (c)intr-aparticle diffusion model.

((pH of 6, Pb(II) concentration (20.0 ppm), contact time range of (5.0-180.0 min), volume of the solution (40 ml), adsorbent dosage (0.04g), and temperature range of (298K))

\begin{tabular}{lll}
\hline Models & Parametrs & Data \\
\hline Pseudo first-order & $\mathrm{q}_{\mathrm{e}}$ & 10.26 \\
& $\mathrm{~K}_{1}$ & 0.0356 \\
& $\mathrm{R}^{2}$ & 0.8547 \\
Pseudo second-order & $\mathrm{q}_{\mathrm{e}}$ & 18.518 \\
& $\mathrm{~K}_{2}$ & 0.00508 \\
Intraparticle diffusion & $\mathrm{R}^{2}$ & 0.9975 \\
& $\mathrm{C}$ & 1.472 \\
& $\mathrm{~K}_{\mathrm{i}}$ & 2.0146 \\
& $\mathrm{R}^{2}$ & 0.9933 \\
\hline
\end{tabular}

Table 3. Kinetic- model parameters for the adsorption of Pb(II) on MIL53(Al)

\section{Comparison of adsorption parameter for $\mathrm{Pb}(\mathrm{II})$ on different adsorbents}

Table 4 compares the lead removal data using various adsorbents. It was found that a significantly small amount of UAS MIL-53(Al) had a moderately better adsorption ability than other samples in a short time. The difference in adsorption rate and capacity of the listed adsorbents lies in different conditions of the adsorption performance, such as temperature, the mass of adsorbent, contact time, the volume of the solution, and difference in surface areas and functional groups. Principally, UAS MIL-53(Al) managed to have a very high adsorption rate of $97.63 \%$ in comparison to some other adsorbents at $\mathrm{pH} \mathrm{6,} \mathrm{due} \mathrm{to} \mathrm{its} \mathrm{hierarchical} \mathrm{structure} \mathrm{and} \mathrm{vaster} \mathrm{surface}$ area. 


\begin{tabular}{|c|c|c|c|c|c|c|c|c|}
\hline Adsorbent & $\begin{array}{c}\mathrm{C}_{\mathrm{i}} \\
(\mathrm{ppm})\end{array}$ & $\begin{array}{l}\text { Contact } \\
\text { time } \\
(\min )\end{array}$ & $\begin{array}{c}\text { Mass of } \\
\text { adsorbent }\end{array}$ & $\mathrm{pH}$ & $\begin{array}{c}\mathrm{q} \\
(\mathrm{mg} / \mathrm{g})\end{array}$ & $\mathrm{T}(\mathrm{K})$ & $\begin{array}{l}\text { Adsorption } \\
\text { efficiency }\end{array}$ & Ref. \\
\hline UAS MIL-53(Al) & 20 & 60 & $0.04 \mathrm{~g}$ & 6 & 19.526 & 318 & 97.63 & $\begin{array}{l}\text { This } \\
\text { study }\end{array}$ \\
\hline SAPO-5 & 60 & 180 & $0.12 \mathrm{~g}$ & $5-6$ & 17.29 & - & 80.5 & 34 \\
\hline AIPO-5 & 60 & 180 & $0.12 \mathrm{~g}$ & $5-6$ & 19.9 & - & 84.5 & 34 \\
\hline $\begin{array}{c}\text { AMCA- } \\
\text { MIL53(Al) }\end{array}$ & 400 & 120 & $0.075 \mathrm{~g}$ & 5.8 & 390 & 318 & 92 & 12 \\
\hline $\begin{array}{l}\text { Magnetic } \\
\text { chrysotile } \\
\text { Nanotubes }\end{array}$ & 21.4 & - & $0.57 \mathrm{~g} / 1$ & 5 & 27.64 & 298 & - & 37 \\
\hline Mesoporous silica & 828 & 20 & $0.05 \mathrm{~g}$ & 6 & 84.49 & - & 51 & 38 \\
\hline ED-MIL-101(Cr) & 50 & 30 & $0.02 \mathrm{~g}$ & 6 & 81.5 & 298 & - & 39 \\
\hline
\end{tabular}

Table 4. Comparison of adsorption parameter for $\mathrm{Pb}(\mathrm{II})$ on different adsorbents

\section{Regeneration of adsorbent}

The regeneration efficiency of UAS MIL-53(Al) as an adsorbent was evaluated with various elements such as $\mathrm{H} 2 \mathrm{SO} 4, \mathrm{H} 2 \mathrm{SO}$, and $\mathrm{HCl}$. $\mathrm{HCL} 0.1 \mathrm{M}$ as a strong acid was discovered to be the best desorption of $\mathrm{Pb}$ ion to wash the adsorbent with it, rewash it with distilled water, and dry and check its recyclability adsorbent. $0.1 \mathrm{M} \mathrm{HCl}$ was used to wash up the $\mathrm{Pb}$ (II) for one cycle. The Comparison of adsorption for $\mathrm{Pb}(\mathrm{II})$ on Conversion and Ultrasonic synthesis and regeneration of adsorbent in one cycle has shown in Figure14. 


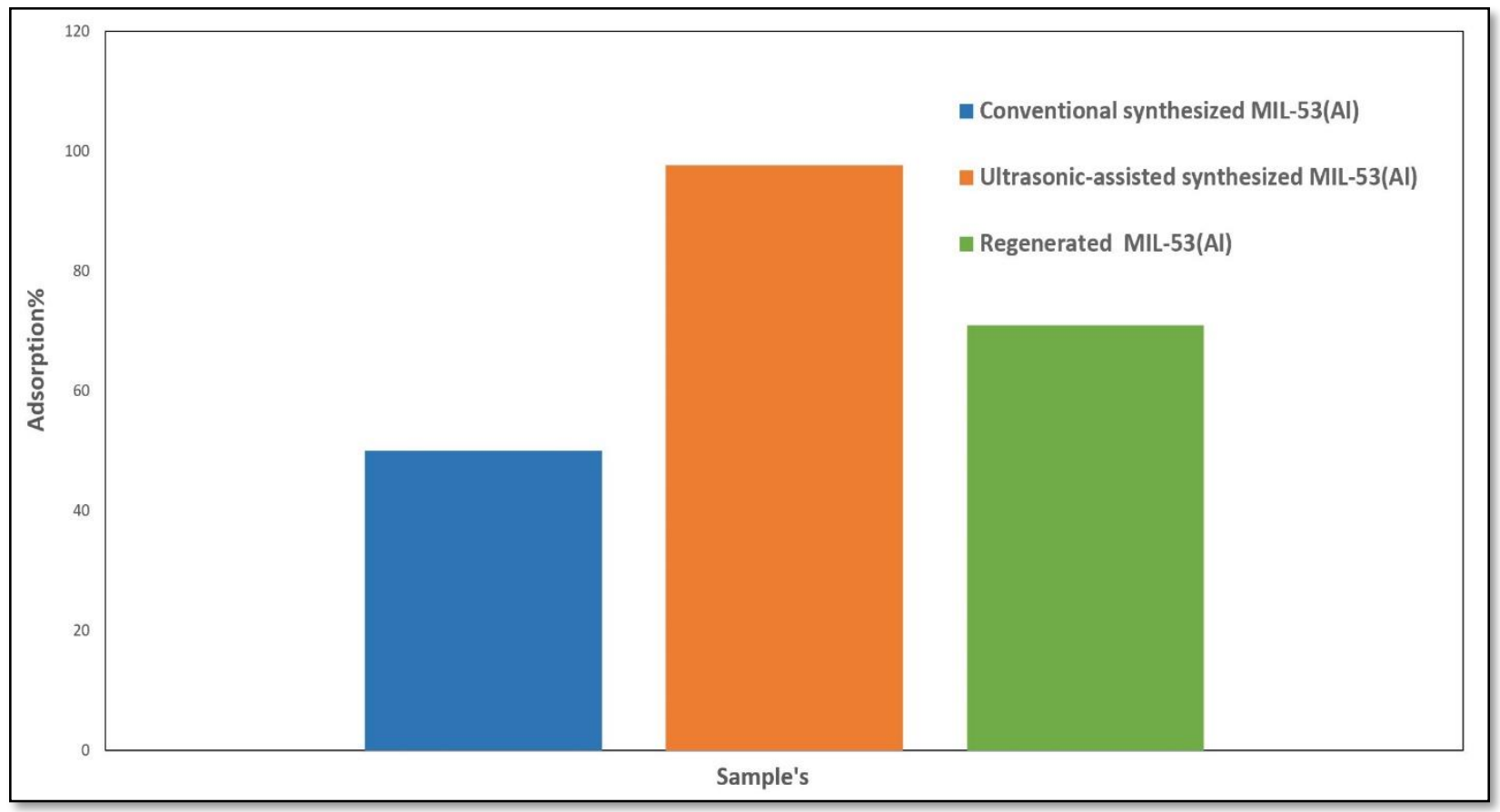

Figure 14.Comparison of adsorption parameter for $\mathrm{Pb}$ (II) on Conventional and Ultrasonic assisted synthesized and 1cycle regeneration of adsorbent

\section{Conclusion}

In the reported study, an efficient and fast method was used to prepare MIL-53(Al), and its impact on the adsorption properties for removing lead ions from aqueous solution was examined. It demonstrates that this Ultrasonic-assisted synthesized MIL-53(Al) can remove lead ions effectively. Compared to conventional synthesis, the sonochemical synthesis managed to shorten the time duration of synthesis from 3 days to 1 day, leading to a faster reaction rate, a hierarchical structure, and a higher external surface area of $1538.6 \mathrm{~m} 2 / \mathrm{g}$ and average pore size.

Also, UAS MIL-53(Al) showed a highly effective adsorbent. Compared to other research pieces of literature, the present study proved that increasing the crystallinity and external surface area of MIL-53(Al) lead to significant removal of lead ions due to the synthesis method. The optimal conditions for lead adsorption were achieved using $0.04 \mathrm{mg}$ of adsorbent, $60 \mathrm{~min}$ contact time as equilibrium time, an initial concentration $(20.0 \mathrm{mg} / \mathrm{L})$, and maximum $\mathrm{pH}$ of 6 . The higher volume of adsorbent and the longer contact time were found to be factors in increasing the adsorption rate. UAS MIL-53(Al) confirmed the adsorption rate of $97.63 \%$ at $315 \mathrm{k}$ temperature, which was shown to increase adsorption with the increasing temperature, meaning that adsorption would be 
endothermic. The kinetic data followed a pseudo-second-order rate equation where lead ions were adsorbed onto various sites at different points and had a fast adsorption rate. Data fitted the Langmuir isotherm model, and dynamic and equilibrium surfaces formed perfectly homogeneous surfaces, hence a monolayer coating. In summary, it is expected to use UAS MIL-53(Al) as a promising adsorbent for lead removal from aqueous solutions.

\section{References}

1. Khoso, W. A., Haleem, N., Baig, M. A. \& Jamal, Y. Synthesis, characterization and heavy metal removal efficiency of nickel ferrite nanoparticles (NFN's). Sci. Rep. 11, 1-10 (2021).

2. Alsuhybani, M., Alshahrani, A., Algamdi, M., Al-Kahtani, A. A. \& Alqadami, A. A. Highly efficient removal of $\mathrm{Pb}$ (II) from aqueous systems using a new nanocomposite: Adsorption, isotherm, kinetic and mechanism studies. J. Mol. Liq. 301, 112393 (2020).

3. Jafari, Z., Avargani, V. M., Rahimi, M. R. \& Mosleh, S. Magnetic nanoparticlesembedded nitrogen-doped carbon nanotube/porous carbon hybrid derived from a metalorganic framework as a highly efficient adsorbent for selective removal of $\mathrm{Pb}(\mathrm{II})$ ions from aqueous solution. J. Mol. Liq. 318, 113987 (2020).

4. Zhang, D., Yin, C., Abbas, N., Mao, Z. \& Zhang, Y. Multiple heavy metal tolerance and removal by an earthworm gut fungus Trichoderma brevicompactum QYCD-6. Sci. Rep. 10, 1-9 (2020).

5. Sadeghi Chevinli, A., Najafi, M. \& Sillanpää, M. Removal of La(III) ions from aqueous solution by Lanthanide MOF; characterization, synthesizing and process conditions study. Environ. Nanotechnology, Monit. Manag. 12, 100216 (2019).

6. A. Mannaa, M., Altass, H. M. \& Salama, R. S. MCM-41 grafted with citric acid: The role of carboxylic groups in enhancing the synthesis of xanthenes and removal of heavy metal ions. Environ. Nanotechnology, Monit. Manag. 15, 100410 (2021).

7. Vahdat, A., Ghasemi, B. \& Yousefpour, M. Synthesis of hydroxyapatite and hydroxyapatite/Fe3O4 nanocomposite for removal of heavy metals. Environ. Nanotechnology, Monit. Manag. 12, 100233 (2019).

8. Kaur, H., Sinha, S., Krishnan, V. \& Koner, R. R. Photocatalytic Reduction and Recognition of Cr(VI): New Zn(II)-Based Metal-Organic Framework as Catalytic Surface. Ind. Eng. Chem. Res. 59, 8538-8550 (2020).

9. Zhang, Y. et al. Constructing free standing metal organic framework MIL-53 membrane based on anodized aluminum oxide precursor. Sci. Rep. 4, 2-7 (2014).

10. Mishra, P., Uppara, H. P., Mandal, B. \& Gumma, S. Adsorption and separation of carbon dioxide using MIL-53(Al) metal-organic framework. Ind. Eng. Chem. Res. 53, 1974719753 (2014).

11. Panda, J. et al. Efficient removal of two anionic dyes by a highly robust zirconium based 
metal organic framework from aqueous medium: Experimental findings with molecular docking study. Environ. Nanotechnology, Monit. Manag. 14, 100340 (2020).

12. Alqadami, A. A., Khan, M. A., Siddiqui, M. R. \& Alothman, Z. A. Development of citric anhydride anchored mesoporous MOF through post synthesis modification to sequester potentially toxic lead (II) from water. Microporous Mesoporous Mater. 261, 198-206 (2018).

13. Abdpour, S. et al. Amino-functionalized MIL-101(Cr) photodegradation enhancement by sulfur-enriched copper sulfide nanoparticles: An experimental and DFT study. J. Mol. Liq. 319, 114341 (2020).

14. Kalhor, S. et al. Anodic electrosynthesis of MIL-53(Al)-N(CH2PO3H2)2 as a mesoporous catalyst for synthesis of novel (N-methyl-pyrrol)-pyrazolo[3,4-b]pyridines via a cooperative vinylogous anomeric based oxidation. Sci. Rep. 11, 1-20 (2021).

15. Bakhtiari, N. \& Azizian, S. Adsorption of copper ion from aqueous solution by nanoporous MOF-5: A kinetic and equilibrium study. J. Mol. Liq. 206, 114-118 (2015).

16. Verma, A., Agarwal, M., Sharma, S. \& Singh, N. Competitive removal of cadmium and lead ions from synthetic wastewater using Kappaphycus striatum. Environ. Nanotechnology, Monit. Manag. 15, 100449 (2021).

17. Yan, J., Jiang, S., Ji, S., Shi, D. \& Cheng, H. Metal-organic framework MIL-53(Al): Synthesis, catalytic performance for the Friedel-Crafts acylation, and reaction mechanism. Sci. China Chem. 58, 1544-1552 (2015).

18. Askari, S. \& Halladj, R. Effects of ultrasound-related variables on sonochemically synthesized SAPO-34 nanoparticles. J. Solid State Chem. 201, 85-92 (2013).

19. Ge, J., Liu, L., Qiu, L., Jiang, X. \& Shen, Y. Facile synthesis of amine-functionalized MIL-53(Al) by ultrasound microwave method and application for CO2 capture. J. Porous Mater. 23, 857-865 (2016).

20. Silvester, L. et al. Fine tuning of the physico-chemical properties of a MIL-53(Al) type Mesoporous alumina composite using a facile sacrificial-template synthesis approach. Microporous Mesoporous Mater. 306, 110443 (2020).

21. Rallapalli, P. et al. An alternative activation method for the enhancement of methane storage capacity of nanoporous aluminium terephthalate, MIL-53(Al). J. Porous Mater. 17, 523-528 (2010).

22. Qian, X. et al. Structure stability of metal-organic framework MIL-53 (Al) in aqueous solutions. Int. J. Hydrogen Energy 38, 16710-16715 (2013).

23. Askari, S. \& Halladj, R. Ultrasonic pretreatment for hydrothermal synthesis of SAPO-34 nanocrystals. Ultrason. Sonochem. 19, 554-559 (2012).

24. Shi, Q., Qin, Y., Zhou, B. \& Wang, X. Porosity changes in bituminous and anthracite coal with ultrasonic treatment. Fuel 255, 115739 (2019).

25. Azarhoosh, M. J., Halladj, R., Askari, S. \& Aghaeinejad-Meybodi, A. Performance 
analysis of ultrasound-assisted synthesized nano-hierarchical SAPO-34 catalyst in the methanol-to-lights-olefins process via artificial intelligence methods. Ultrason. Sonochem. 58, 104646 (2019).

26. Loiseau, T. et al. A Rationale for the Large Breathing of the Porous Aluminum Terephthalate (MIL-53) Upon Hydration. Chem. - A Eur. J. 10, 1373-1382 (2004).

27. Wahab, M. A., Jellali, S. \& Jedidi, N. Effect of temperature and pH on the biosorption of ammonium onto Posidonia oceanica fibers: Equilibrium, and kinetic modeling studies. Bioresour. Technol. 101, 8606-8615 (2010).

28. Ho, Y. S. \& McKay, G. The kinetics of sorption of basic dyes from aqueous solution by sphagnum moss peat. Can. J. Chem. Eng. 76, 822-827 (1998).

29. Cornell, R. M. \& Schwertmann, U. Thermodynamics of the Fe-O 2 -H 2 O System . Iron Oxides 185-199 (2003) doi:10.1002/3527602097.ch8.

30. Zhou, Y. T., Nie, H. L., Branford-White, C., He, Z. Y. \& Zhu, L. M. Removal of Cu2+ from aqueous solution by chitosan-coated magnetic nanoparticles modified with $\alpha$ ketoglutaric acid. J. Colloid Interface Sci. 330, 29-37 (2009).

31. Basha, S., Murthy, Z. V. P. \& Jha, B. Sorption of Hg(II) from aqueous solutions onto Carica papaya: Application of isotherms. Ind. Eng. Chem. Res. 47, 980-986 (2008).

32. Hall, K. R., Eagleton, L. C., Acrivos, A. \& Vermeulen, T. Pore- and solid-diffusion kinetics in fixed-bed adsorption under constant-pattern conditions. Ind. Eng. Chem. Fundam. 5, 212-223 (1966).

33. Ghaedi, A. M. et al. Factorial experimental design for the optimization of highly selective adsorption removal of lead and copper ions using metal organic framework MOF-2 (Cd). J. Mol. Liq. 272, 15-26 (2018).

34. Biriaei, R., Halladj, R. \& Askari, S. Heavy Metal Ions Uptake by AlPO-5 and SAPO-5 Nanoparticles: An Experimental and Modeling Study. Water Environ. Res. 89, 337-347 (2017).

35. Saleh, T. A. \& Al-Absi, A. A. Kinetics, isotherms and thermodynamic evaluation of amine functionalized magnetic carbon for methyl red removal from aqueous solutions. $J$. Mol. Liq. 248, 577-585 (2017).

36. Zhang, W. et al. Enhanced heavy metal removal from an aqueous environment using an eco-friendly and sustainable adsorbent. Sci. Rep. 10, 1-19 (2020).

37. Yu, S. et al. Synthesis of magnetic chrysotile nanotubes for adsorption of $\mathrm{Pb}(\mathrm{II}), \mathrm{Cd}(\mathrm{II})$ and $\mathrm{Cr}(\mathrm{III})$ ions from aqueous solution. J. Environ. Chem. Eng. 3, 752-762 (2015).

38. Yang, H., Xu, R., Xue, X., Li, F. \& Li, G. Hybrid surfactant-templated mesoporous silica formed in ethanol and its application for heavy metal removal. J. Hazard. Mater. 152, 690-698 (2008).

39. Luo, X., Ding, L. \& Luo, J. Adsorptive removal of $\mathrm{Pb}(\mathrm{II})$ ions from aqueous samples with amino-functionalization of metal-organic frameworks MIL-101(Cr). J. Chem. Eng. Data 
60, 1732-1743 (2015). 